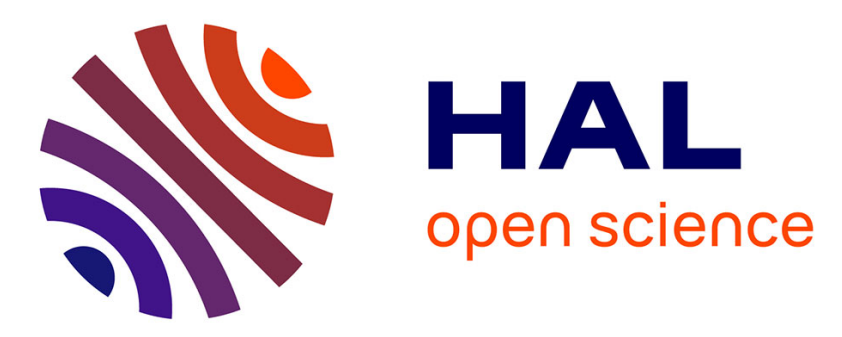

\title{
Sexual odor discrimination and physiological profiles in adult male rats after a neonatal, short term, reversible nasal obstruction
}

\author{
Simon N. Thornton, G. S. Padzys, Marie Trabalon
}

\section{- To cite this version:}

Simon N. Thornton, G. S. Padzys, Marie Trabalon. Sexual odor discrimination and physiological profiles in adult male rats after a neonatal, short term, reversible nasal obstruction. Brain Research Bulletin, 2014, 104, pp.74-81. 10.1016/j.brainresbull.2014.04.009 . hal-01021470

\author{
HAL Id: hal-01021470 \\ https://hal.science/hal-01021470
}

Submitted on 5 Sep 2014

HAL is a multi-disciplinary open access archive for the deposit and dissemination of scientific research documents, whether they are published or not. The documents may come from teaching and research institutions in France or abroad, or from public or private research centers.
L'archive ouverte pluridisciplinaire HAL, est destinée au dépôt et à la diffusion de documents scientifiques de niveau recherche, publiés ou non, émanant des établissements d'enseignement et de recherche français ou étrangers, des laboratoires publics ou privés. 
Sexual odor discrimination and physiological profiles in adult male rats after a neonatal, short term, reversible nasal obstruction

S. N. Thornton ${ }^{1 *}$, G.S. Padzys ${ }^{2}$, M. Trabalon ${ }^{3}$

${ }^{1}$ Université de Lorraine, U1116 INSERM-UL, B.P.70239, 54506 Vandœuvre-Les-Nancy,

France ; ${ }^{2}$ Université Des Sciences et Techniques de Masuku, Franceville, Gabon ; ${ }^{3}$ Université de Rennes 1, UMR 6552 CNRS EthoS, 35042 Rennes, France.

Running title: Adult sex odor preferences after neonatal reversible nasal obstruction

Word count body of manuscript: 3925 (without references)

2 tables, 6 figures

* To whom correspondence should be addressed:

Prof. Simon Thornton

Université de Lorraine, U1116 INSERM-UL

54505 Vandoeuvre-Les-Nancy - France

E-mail : simon.thornton@univ-lorraine.fr 


\begin{abstract}
The present study was designed to examine behavioral responses (interpreted as preferences) to olfactory cues (nest bedding odor and odors of estrous and anestrus females) in adult male rats after they had had a short term reversible, bilateral, nasal obstruction (RbNO) as developing rat pups. These results were compared to behavior of control (untreated) and sham operated male littermates. Behavioral tests and physiological parameters were analyzed 90 days after recovery of nasal breathing. Experiments investigated the time spent in arms or the centre of a maze of male rats in response to odors from the nest bedding or from adult females. There were no differences in responses between untreated, sham and RbNO adult male rats to fresh and nest bedding odors. RbNO males spent more time in the centre of the maze when given a choice of estrus or anestrus female odors, or bedding odors from untreated or sham operated female rats. In contrast untreated and sham male rats preferred the odors of estrous females and of untreated or sham females. Plasma corticosterone levels in the males increased during the behavioral tests. Plasma testosterone levels were significantly lower in RbNO males compared to untreated males and did not increase during the behavioral tests compared to sham operated males. Males from all groups had similar preferences for the odor of bedding from adult RbNO females. Plasma levels of cholesterol and triglycerides were increased in $\mathrm{RbNO}$ adults. In conclusion, short term nasal obstruction in males while juvenile has long term consequences on hormones and behavioral preferences, thus potential partner selection when adult.
\end{abstract}

\title{
Word count body of abstract: 260
}

Keywords: hormones, nasal obstruction, postnatal development, chemosensory, sex odor preference 


\section{Introduction}

Under normal conditions lack of olfaction is generally associated with the obstruction of the nasal cavities (Seiden and Duncan, 2001) which, if carried out early, could have negative effects on subsequent adult activities as growth of the neuronal population in the olfactory bulb extends up to post-natal day 20 (Bayer, 1983). Our previous study revealed indeed that reversible, bilateral, nasal obstruction $(\mathrm{RbNO})$ induced in eight-day old rats led to an activation of the stress response with increased corticosterone as the final effecter (Gelhaye et al., 2006 a, b). The literature shows that increased plasma levels of corticosterone are associated with the expression of anxiety-related behaviors such as hyperactivity (Cao et al., 2007), with modifications of novelty-seeking behavior (Alemany, 2008; Gelhaye et al., 2006b, 2011), and social play in juvenile rats (Beatty and Costello, 1983; Risser and Slotnick, 1987).

Through olfactory deprivation and activation of the HPA axis, early nasal obstruction could disrupt, on the one hand establishment of exploratory behavior, a preliminary necessary for the emancipation and the dispersion of young mammals, and on the other hand the hormonal homeostasis of young individuals (Leon, 1992; Rossier and Schenk, 2003). Nasal obstruction generates numerous effects on the olfactory bulb, including reduction of its volume (Gelhaye et al., 2006a; Padzys et al. 2012) and a variety of neurochemical and functional changes (Brunjes, 1994). However, in spite of the blockage of the nasal cavities, odorants could, theoretically, reach the olfactory epithelium via the nasopharynx and this retronasal perception could mediate odor-guided behaviors in rodents (Coppola et al., 1994; Chapuis et al., 2007).

In many species, including humans, chemosensory stimuli function as social cues that impact reproductive hormones and behavior (Doty, 2001; Jacob et al., 2001; WirsigWiechmann, 2001). In rodents, female odors (or pheromones) activate neurons in limbic circuits mediating male reproductive behavior and elicit gonadal steroid release in sexually naïve males (Meredith, 1998). The expression of reproductive behavior in sexually naïve male Syrian hamsters is absolutely dependent on female pheromones present in vaginal secretions and their transduction by the vomeronasal system (Meredith, 1986; Meredith and Howard, 1992). In male hamsters and rats, exposure to female pheromones elicits a rise in testosterone within $60 \mathrm{~min}$ (Richardson et al., 2004; Wood et al. 2004). Furthermore, female chemosensory stimuli can be used to establish a classically conditioned endocrine response to 
a neutral stimulus, confirming their roles as unconditioned stimuli for evoking reproductive responses in males (Graham and Desjardins, 1980).

Olfactory recognition often appears to be important in establishing the bond between mammalian individuals. The young distinguish their own mother from other females by recognizing her distinctive odor (Hongo et al. 2000). An early imprinting with the correct odor may influence not only the young animal's future recognition of and relations with its mother, but also its selection of a mate having a similar odor when it becomes adult. Mammalian pheromones used for individual recognition may volatilize directly from the body of the animal, or it may be deposited onto a substratum as a scent mark. A scent mark has the advantage of allowing an animal to identify the previous presence of either a known or an unknown individual of the same species in a particular area (Calamandrei 2004). These scent marks may act as loci for the general exchange of information such as the individual identity, as well as the age, sex, breeding condition, and social status of the marking animals (MüllerSchwarze, 1971; Hudson, 1993).

The aim, therefore, of the present study was to evaluate in 110 days old adult male rats the effect of neonatal $\mathrm{RbNO}$ on normal exploratory behavior and on sexual odor differentiation. For the latter we used uniquely odor cues as it is well known that rats make ultrasonic vocalization during mating (Barfield and Thomas, 1986; Matochik and Barfield, 1991). The effects of early olfactory deprivation on the stress response (corticosterone) on plasma levels of sexual hormones (progesterone, oestradiol and testosterone), and biochemical states (glucose, proteins, lipids) were also studied in adult rats.

Our hypothesis was that early short-term olfactory deprivation (RbNO) would have a significant effect of some parameters of exploratory and/or prosexual behavior. Nest bedding odor recognition and choice of sexual partner odor (bedding from estrus and anestrus females) were therefore investigated in a two-choice situation. As vertebrates are frequently characterized as being able to recognize the physiological status of a sexual partner, we therefore tested also the choice of odors (anestrus) from untreated, sham or early nasally obstructed female rats in a three choice situation.

\section{Methods}

\subsection{Animal care}


Male and female Wistar rats (origin IFFA- CREDO) were used in these experiments. These pups were born in the laboratory from 15 litters, culled to 10 pups per litter ( 5 males and 5 females) to ensure normal body growth. We used three male from each litter for each of the biological and behavioral tests. We used all females from each litter for behavioral tests. The animals were housed in standard cages under controlled temperature conditions $\left(22 \pm 1^{\circ} \mathrm{C}\right)$. Food (pellets of $12 \mathrm{~mm}$, Harlan Interfauna Iberica SA) and water were available ad libitum throughout the experiment. From birth, the rats were kept on a reversed 12:12 light-dark cycle (dark period 08:00-20:00h).

Methods were schematically in figure 1.

\subsection{Nasal obstruction procedure}

At the time of the experiments they conformed to the Guide for the Care and Use of Laboratory Animals published by the National Institutes of Health (no. 85-23, revised 1996), the recommendations of the European Community Council for the Ethical Treatment of Animals (no. 86/609/EEC) and the regulations of the University of Lorraine. All efforts were made to minimize animal suffering.

At 8 days of age, the litters were first anesthetized by hypothermia $\left(10 \mathrm{~min}\right.$ at $\left.-18^{\circ} \mathrm{C}\right)$, then weighed and then semi randomly divided into one untreated group, one control group (sham) and one experimental group (reversible, bilateral, nasal obstruction or RbNO). RbNO resulting in forced oral breathing was performed in experimental animals (15 per group and sex from five litters) as described previously by Gelhaye et al. (2006a, b; 2011) and Padzys et al. (2011a, b). The selected method, under cold anesthesia, consisted in cauterizing the external nostrils, which is the most common and simple procedure allowing reversible nasal obstruction in neonates. The tissue surrounding the external nostrils was burned by placing a surgical cauterizing instrument (1 $\mathrm{mm}$ in diameter) on the nostrils, consequently occluding the orifice of the nostrils without mechanical or chemical damage to the olfactory mucosa. This procedure induced complete nasal obstruction between D8 and D11 with $100 \%$ of the nostrils reopened, bubble formation when tested with a mild soap solution, at D15 (Padzys et al., 2012).

In the sham group ( $\mathrm{SH}$ ), the nostrils were not sealed but the cauterizing instrument was placed about 1-2 mm above each nostril (15 per group and sex from five litters). After cauterization, the nostrils were washed with chlortetracycline (Aureomycine Evans 3\%) to prevent 
infection. In the untreated group (UT) the rats were anesthetized only (15 per group and sex from five litters).

The pups were warmed $\left(37^{\circ} \mathrm{C}\right)$ for $30 \mathrm{~min}$ and returned to their mothers. The pups were weaned at 25 days of age and then housed in a cage with 2 conspecifics of the same sex and treatment. Animals were left undisturbed until the onset of behavioural testing and sample collection at $90 \pm 4$ days after post-reopening of the nostrils (D110). As shown schematically in Figure 1.

\subsection{Behavioral analysis:}

All tests were carried out during the dark period under red light.

Evaluation of physiological state (estrus or anestrus) of females: Females were tested behaviorally in a semi-circular arena $(\mathrm{r}=30 \mathrm{~cm})$ under dim red light, 10 min before odor partner preference test. The females were introduced into the cage containing a test male, who was allowed 6 mounts. Female lordosis behaviour (taken as a sign of estrus) and male mount frequency were scored for $10 \mathrm{~min}$. Bedding of mounted females (estrus) and bedding of females that had refused mounting (taken as a sign of anestrus) were used for the odor partner test.

Odor partner preference with no physical interaction tests: For behavioral observations we used a T-maze and a radial arm maze. The T-maze presented a start arm connected to two goal arms of equal dimensions $(30 \mathrm{~cm} \times 10 \mathrm{~cm} \times 10 \mathrm{~cm})$. The maze was constructed of Plexiglas, with a guillotine door separating the start box from the main stem of the maze. An experimental box $(40 \mathrm{~cm} \times 20 \mathrm{~cm} \times 15 \mathrm{~cm})$ was situated at the end of each goal arm and closed by a door with holes in it which allowed stimulation by smell. The radial arm maze was an array of three arms $(30 \mathrm{~cm} \times 10 \mathrm{~cm} \times 10 \mathrm{~cm})$ radiating from a central starting area. At the end of each arm we placed an experimental glass box $(40 \mathrm{~cm} \times 20 \mathrm{~cm} \times 15 \mathrm{~cm})$. In all cases, $45 \pm 5 \mathrm{~g}$ of bedding material were placed in the experimental boxes and each peripheral box, placed at random, were presented only once. Each experimental box was tested only once. The experimental set-up was washed with an acetone-water solution (5\%) between each test to obviate possible biasing effects of odor by the previous rats nest bedding.

Two-Choice situation in T-maze. In order to evaluate exploratory behavior, the adult male rats were observed during $10 \mathrm{~min}$ in the two-choice situation "fresh bedding versus nest 
bedding of a male", then immediately after for evaluate their pro-sexual olfactory ability with "nest bedding of an UT estrus female versus nest bedding of an UT anestrus female". The observation period (10 min) began when the rat entered the start arm of the T-maze and the guillotine door was closed behind it. The latency of the first choice (defined by the first contact between an animal and a lateral box), and the time spent with sniffing in each arm of the T-maze were recorded.

Three-Choice situation in radial arm maze. Immediately after the behavioral observations in the T-maze, males were placed in the central box of the radial arm maze and allowed to choose between a box with "nest bedding of UT estrus female", a box with "nest bedding of a SH estrus female", a box with "nest bedding of an RbNO estrus female". Females were the same age as the male, $110 \pm 4$ days.

The behavioral observation began the second the experimental rat touched the substratum of the central box and the tested rat was observed for 10 min after the first contact with one test box. The latency of the first choice (defined by the first contact between an animal and an experimental box), and the time spent with sniffing in each arm of the radial maze were recorded.

The behavior of all males was videotaped with video tracking equipment and analyzed with the Smart-MA programme (Smart Panlab, Bioseb, France). The events were later quantified by a "blind" tester. To minimize the influences of possible circadian changes on behaviors, untreated, sham and RbNO animals were alternated for observation. They were observed at the same time of day (between 9:00 AM and 11:00 AM). The apparatus was maintained in the same position in the room throughout the duration of the study.

\subsection{Sample collection}

First samples: For hormone assays, rats were anesthesia $24 \mathrm{hr}$ before behavior tests, nasal opening diameters were measured with a caliper and intracardiac blood samplings (500 $1000 \mu \mathrm{l})$ were taken between $11 \mathrm{~h}$ and $12 \mathrm{~h}$ for hormonal measurements. Blood was collected within 1-2 min into sterile heparinised syringes fitted with a 26-G needle. Plasma was immediately separated by centrifugation at $4^{\circ} \mathrm{C}(15 \mathrm{~min}$ at $3000 \mathrm{rpm})$ and the extracts aliquoted and stored at $-36^{\circ} \mathrm{C}$ until the time of assay (corticosterone and testosterone).

Second samples: Immediately after the end of the behavioral observations, rats were anesthesia, weighed and intracardiac blood samplings were taken with same method. Plasma was aliquoted and stored at $-36^{\circ} \mathrm{C}$ until the time of the assay (biochemical and hormones). 


\subsection{Hormone assays}

Corticosterone, progesterone, $17 \beta$-estradiol and testosterone concentrations were measured without an extraction procedure, using a commercially available EIA kit and performed according to the manufacturer's guidelines (Assay Designs Inc., USA). The concentration of hormones in plasma samples was calculated from a standard curve and expressed as $\mathrm{ng} / \mathrm{ml}$ for corticosterone and $\mathrm{pg} / \mathrm{ml}$ for sexual hormones. The intra- and inter-assay coefficients of variation were under $8.4 \%$ and $13.1 \%$ respectively for corticosterone, $9.2 \%$ and $7.4 \%$ respectively for progesterone, $7.6 \%$ and $8.3 \%$ respectively for $17 \beta$-estradiol, $10.8 \%$ and $14.6 \%$ respectively for testosterone.

\subsection{Biochemical assays: determination of glucose, protein and lipids levels}

Concentration of blood glucose was determined using a colorimetric method after enzymatic oxidation in the presence of glucose oxidase (Glucose-test, Randox, UK). The hydrogen peroxide that forms then reacts, under catalysis of peroxidase, with phenol and 4aminophenazone to form a red-violet quinoneimine dye as indicator.

Protein content in $10 \mu \mathrm{l}$ of plasma samples was determined according to the method of Bradford (1976) using bovine serum albumin as the standard.

Triglycerides were determined using a colorimetric method after enzymatic hydrolysis with lipases (Triglycerides-test, Randox, UK). The indicator was quinoneimine formed from hydrogen-peroxide, 4-aminophenazone and 4-clorophenol under the catalytic influence of peroxidase.

Cholesterol was determined using colorimetric method after enzymatic hydrolysis and oxidation (Cholesterol-test, Randox, UK). The indicator quinoneimine was formed from hydrogen peroxide and 4-aminoantipyrine in the presence of phenol and peroxidase.

\subsection{Statistical analysis}

The results were expressed as group means \pm SE. Statistical analysis was performed by means of statistical software (Statview V5.0, Abacus concepts Inc., Berkeley, CA).

Statistical analysis was done considering both the experimental condition (UT, Sham or $\mathrm{RbNO}$ ) and whether two or three choice situations were used as factors. Therefore, a two 
factor ANOVA was carried out. The same should be specified for: time spent in each arm of the T-maze, time spent in each arm of the radial arm maze; corticosterone and testosterone before and after behavioral tests. In this last case, the Tukey test was used to establish the inter-group comparison.

Concerning the other physiological data, group differences were determined using analysis of variance (one way ANOVA). Analysis of Specific mean comparisons were then made using Tukey test.

In all cases, the differences were considered significant at $\mathrm{P}<0.05$.

\section{Results}

\subsection{Behavior tests}

\section{Exploratory behavior during two-choice situation in T-maze}

During the first test, "fresh bedding $v s$ nest bedding", no differences $(\mathrm{P}=0.22)$ were observed between the three groups of males for latency of the first choice (Figure 2A). Rats chose more quickly the fresh bedding box $(\mathrm{P}=0.03)$.

The time spent in each arm (Fig. 3A) was comparable with the three groups $(\mathrm{P}=0.18)$. The males spent approximately $80 \%$ of time $(428 \mathrm{sec})$ to explore-sniffing the T-maze.

\section{Pro-sexual behavior during two-choice situation in T-maze}

The latency of the 1st choice (Figure 2B) was comparable when SH and UT males had to choose between "nest bedding of estrus females $v s$ nest bedding of anestrus females" $(\mathrm{P}=$ 0.82). RbNO males spent significantly more time in the centre of the maze before going into the box of the "bedding estrus females" than other males $(\mathrm{F}=4.01, \mathrm{P}=0.02)$.

Fig. 3B shows that the induction of nasal obstruction affected the time repartition inside the maze with "nest bedding estrus female $v s$ nest bedding anestrus female" (analysis of two-way ANOVA: treatment effect: $\mathrm{F}=173.66, \mathrm{P}<0.0001$; time spent in each arm: $\mathrm{F}=$ 51.83, $\mathrm{P}<0.0001$; treatment*time: $\mathrm{F}=3.52, \mathrm{P}=0.05) . \mathrm{RbNO}$ animals spent more time in the centre of the maze and thus less time in the nest sides compared to the untreated and sham males $(p=0.01)$. Sham and untreated rats spent significantly more time in the box of "estrus females" $(p<0.005)$. 


\section{Social recognition during three-Choice situation in radial arm maze}

During the three-choice test, no differences were observed between the three groups of males for latency of the first choice: $18.1 \pm 1.3 \mathrm{sec}$ for untreated rats, $17.9 \pm 1.2 \mathrm{sec}$ for sham rats, and $20.5 \pm 2.1 \mathrm{sec}$ for $\mathrm{RbNO}$ rats $(F=1.77, \mathrm{P}=0.14)$.

Fig. 4 shows that differences were observed between RbNO and the two groups of males (UT and $\mathrm{SH}$ ) for total time spent in each arm (analysis of two-way ANOVA: treatment effect: $\mathrm{F}=73.95, \mathrm{P}<0.0001$; time spent in each arm: $\mathrm{F}=99.78, \mathrm{P}<0.0001$; treatment*time: $\mathrm{F}=13.54, \mathrm{P}=0.001) . \mathrm{RbNO}$ males spent less time in the "bedding untreated" and "bedding sham" and significantly more time in the center of the radial arm than the other males $(p=$ $0.01)$.

No significant differences were observed between the three groups of male rats and time spends in the box of "bedding RbNO females". Sham and untreated rats spent significantly less time in the center radial arm $(p=0.01)$.

\subsection{Body weight and Biochemical assay}

Before the treatment, at 8 days of age, the weights of the three groups of rat pups were not significantly different $(\mathrm{F}=3.80, \mathrm{P}=0.18)$ : $17.8 \pm 0.4 \mathrm{~g}$. Table 1 shows that the weights were similar also at adulthood: $405 \pm 13 \mathrm{~g}(\mathrm{~F}=1.86, \mathrm{P}=0.17)$. After recovery of nasal breathing the diameter of the nasal opening in $\mathrm{RbNO}$ rats was slightly but significantly smaller than in the control and sham rats $(\mathrm{F}=7.22, \mathrm{P}=0.004)$ but it did not prevent them from breathing through the nose.

No differences were observed in male plasma glucose $(\mathrm{F}=1.07, \mathrm{P}=0.35)$ and proteins levels $(\mathrm{F}=1.17, \mathrm{P}=0.32)$ between $\mathrm{RbNO}$, sham and untreated rats. Levels of cholesterol and triglycerides in $\mathrm{RbNO}$ male rats were significantly higher than sham and untreated males $(\mathrm{F}=$ $4.51, \mathrm{P}=0.02$ and $\mathrm{F}=3.26, \mathrm{P}=0.05$, respectively).

\subsection{Hormonal assay}

Corticosterone. Short term nasal obstruction produced a significant increase in plasma corticosterone levels compared with sham and untreated males. As shown in fig. 5, behavioural tests produced a significant increase in plasma corticosterone levels in the three 
groups of males. The concentration of corticosterone was significantly higher in RbNO rats before and after the behavioral tests (analysis of two-way ANOVA: treatment effect: $\mathrm{F}=4.75$, $\mathrm{P}<0.05$; time: $\mathrm{F}=4.90, \mathrm{P}<0.05$; treatment*time: $\mathrm{F}=6.80, \mathrm{P}=0.01$.

Sexual hormones. Fig. 6 shows that plasma testosterone levels were significantly different between the experimental groups before and after the behavioral tests (analysis of two-way ANOVA: treatment effect: $\mathrm{F}=8.96, \mathrm{P}<0.001$; time: $\mathrm{F}=12.69, \mathrm{P}<0.0001$; treatment*time: $\mathrm{F}=23.99, \mathrm{P}<0.0001)$. The level of testosterone was significantly lower than in RbNO rats before tests $(p=0.01)$. The level of plasma testosterone increased significantly $(p=0.003)$ after the behavioral tests in SH and in UT rats. The level of plasma testosterone did not vary in $\mathrm{RbNO}$ rats between before and after the behavioral tests: $2.5 \pm 0.7 \mathrm{ng} / \mathrm{ml}$ after tests.

Table 2 shows that there were no significant differences in plasma $17 \beta$-oestradiol and progesterone levels between the three groups after behavioral tests $(\mathrm{F}=2.42, \mathrm{P}=0.09$ and $\mathrm{F}=$ $0.85, \mathrm{P}=0.43$, respectively).

\section{Discussion}

These results show that a short term, precocious, reversal bilateral nasal obstruction (at 8 days postnatal for 5 days) had a profound influence on the reactivity of naïve, adult male rats to odors of same age sexually mature female rats but not to a new environment (fresh bedding) indicating that exploratory and sniffing behavior were normal but sexual cue behavior appeared to be disrupted. Untreated and sham operated male rats of the same age and weight demonstrated normal behavior to the sexual queues as well as to the new environment. Furthermore, the RbNO rats had lower plasma testosterone levels but higher corticoid levels and were more reactive to stress.

The untreated and sham adult naïve male Wistar rats of these experiments demonstrated a clear preference for the odors of receptive (estrus) females as compared with those of non receptive (anestrus) females. Male rats spend more time investigating the arm of a $\mathrm{T}$ maze which contained the odor from a receptive female than the arm which contained the odor from an anestrus female. These results are similar to those for male Sprague-Dawley rats (Stern, 1970). Sex odor preference is very important in the rat's natural environment as it may 
serve as a means for selecting appropriate sexual partners. However, the significance of the odor must be learned as sexual contact is necessary for the preference to appear.

These experiments demonstrate that chemosensory information contained in urine and other secretions from conspecific females activates the HPG axis in sexually naïve adult male rats. Female odors elicited a rapid rise in plasma testosterone without affecting the other sex hormones. These experiments show in the rat an increased plasma androgen level with exposure to female secretions as has been reported previously in hamsters (Macrides et al., 1974; Pfeiffer and Johnston, 1992; Richardson et al., 2004). The increase in testosterone that occurs $30 \mathrm{~min}$ after exposure to pheromones is unlikely to be directly involved in the initial activation of reproductive behavior, as males typically engage in the entire sequence of copulatory behaviors within minutes of being placed with a receptive female (Meek et al., 1997; Romeo et al., 1999). The rise in testosterone after exposure to chemosensory information from the female most likely serves long-term functions, e.g., altering neural or behavioural responses to females in future encounters, or in reinforcing the behavior (Wood et al., 2004).

If a naïve laboratory rat is introduced into a novel environment, the ensuing elevation of corticosterone has been regarded as a function of the novelty of that environment (Pfister and King, 1976). The rapid rise of corticoid levels as a consequence of exposure to a novel environment that we see here has been documented also by others (Bassett et al., 1973; Hennessy and Levine, 1978; Pfister, 1979). Furthermore, an increased level of corticosterone has been shown to reduce the testosterone response (Retána-Marquez et al., 2003) and this is clearly demonstrated here with the rats of these experiments. The novel environment provoked a greatly increased corticosterone response in the RbNO male rats compared to the untreated and sham rats. However, the testosterone response was attenuated in the RbNO animals. In fact it was no different from the levels before the tests indicating perhaps that there was no "sexual" stimulation. In normal rats the detection of receptive female odors is via the vomeronasal organ (Bakker et al., 1996). In contrast to the olfactory bulbs, which are the primary olfactory detection system, the vomeronasal organ does not detect long distance airborne molecules but is very sensitive to those found in close contact with urine of receptive females (O’Connell et al., 1978; Meredith and Fernandez-Fewell, 1994). 
There could be other influences on sexual development that could be responsible for the results presented here. We have remarked already that in the RbNO group during infancy the mother spent more time licking the genital organs of males which at this time increased plasma testosterone levels (Gelhaye et al.; 2011; Padzys et al. 2011a) and this has been shown to be necessary for male rat masculinisation (Moore 1992). Furthermore, the olfactory bulbs of $\mathrm{RbNO}$ rats have been shown to be smaller than controls the day after the induction of blockade as well as at adulthood (Padzys et al., 2012). However, neither of these conditions had any reflection on the weight of the testicles suggesting that here at least development was normal (Padzys et al., 2011a).

It is interesting that nasal obstruction was of only a short duration and very early in the life of the rat but the effects lasted until adulthood. Despite the funding that the narines were of slightly smaller diameter in the RbNO group compared the sham groups, it did not disturb normal exploratory behavior of the environment but uniquely aspects of pro-sexual behavior. This could indicate either lack of sexual maturation, slowed puberty, or an impossibility to differentiate female sex odors through decreased activation of the vomeronasal structure. However, the finding that the RbNO male rats spent more time in the centre of the maze rather than in the arm containing the bedding odor of an estrus female suggests that they could detect the odor but were not attracted by it. This would indicate also that the vomeronasal structure was functioning "normally". Furthermore, the observation that the RbNO males spent more time in the centre of the maze or in the arm with the bedding odor of an RbNO female than in the arms with an untreated or a sham female compared with the untreated or sham males suggests that these rats could detect slight differences in the odors of the different females, and that they were slightly more attracted to the odor of the RbNO females. The physiological or hormonal reason for these results remains to be investigated.

An unusual difference observed in the obstructed rats was increased levels of triglycerides and cholesterol in the plasma. These increased levels could indicate an increased basal level of stress, corroborated by the increased basal level of corticosterone. In stress there is a tendency for plasma levels of glucose to decrease and the release of glycerol and the accompanying triglycerides are needed to maintain these levels (Cahill et al., 1970). However, the rats appeared to behave normally and their exploratory behavior of the novel bedding was the same as the untreated and the sham rats. Increased plasma corticosterone levels support 
the increased plasma cholesterol levels, once again indicating increased stress-induced cholesterol levels (Bryant et al, 1988).

In conclusion, we have shown that short term nasal obstruction in 8 days old male rats can have profound effects of the capacity of these rats when adult to be attracted to sexual odors from mature receptive females. However, it does not appear to have had a negative impact on the capacity to explore a novel environment. The long term consequence of this could influence the sexual behavior of the males and thus their capacity to reproduce. This particular aspect remains to be investigated. 


\section{Conflict of interest}

None declared.

\section{Acknowledgments}

The authors thank Jean-Charles Olry and Cristiane Tankosic for technical assistance. 


\section{References}

Alemany, NR., 2008. Novelty-seeking: its relationship with vulnerability to addiction and stress. Adicciones 20, 59-72.

Bakker, J., Baum, MJ., Slob, AK., 1996. Neonatal inhibition of brain estrogen synthesis alters adult neural Fos responses to mating and pheromonal stimulation in the male rat. Neuroscience 74, 251-260.

Barfield, RJ., Thomas, DA., 1986. The role of ultrasonic vocalization in the regulation of reproduction in rats. Ann. N.Y. Acad Sci. 474, 33-43.

Bassett, JR., Cairneross, KD., King, MG., 1973. Parameters of novelty, shock predictability and response contingency in corticosterone release in the rat. Physiol. Behav. 10, 901-907.

Bayer, SA., 1983. 3H-thymidine-radiographic studies of neurogenesis in the rat olfactory bulb. Exp. Brain Res. 50, 329-340.

Beatty, WW., Costello, KB., 1983. Olfactory bulbectomy and play fighting in juvenile rats. Physiol. Behav. 30, 525-528.

Bradford, MM., 1976. A rapid and sensitive method for the quantification of microgram quantities of protein utilizing the principe of protein_dye binding. Anal. Biochem. 72, 248-254.

Brunjes, PC., 1994. Unilateral naris closure and olfactory system development. Brain Research Rev. 19, 146 - 162.

Bryant, HU., Story, JA., Yim, GKW., 1988. Assement of endogenous opioid mediation in stress-induced hypercholesterolemai in the rat. Psychosomatic Medicine. 50:576-585.

Cahill, GFJr, Marliss, EB., Aoki, TT., 1970. Fat and nitrogen metabolism in fasting man. Horm. Metab. Res. 2, 181-185.

Calamandrei, G., 2004. Ethological and methodological considerations in the use of newborn rodents in biomedical research. Ann. Ist Super Sanita 40, 195-200.

Cao, L., Hudson, CA., Moynihan, JA., 2007. Chronic foot shock induced hyperactive behaviors in mice: involvement of both pro- and anti- inflammatory mediators. $\mathrm{J}$. Neuroimmunology 186, 63-74.

Chapuis, J., Messaoudi, B., Ferreira, G., Ravel, N., 2007. Importance of retronasal and orthonasal olfaction for odor aversion memory in rats. Behv. Neurosci. 126, 1383-1392.

Coppola, DM., Coltrane, JA., Arsov, I., 1994. Retronasal or internasal olfaction can mediate odor-guided behaviours in newborn mice. Physiol. Behav. 56, 729-736.

Doty, RL., 2001. Olfaction. Annu Rev. Psychol. 52, 433-452. 
Gelhaye, M., Martrette, JM., Legrand - Frossi, C., Trabalon, M., 2006a. Myosin heavy chain expression and muscle adaptation to chronic oral breathing in rat. Respiratory Physiol and Neurobiol., 154, 443-452.

Gelhaye, M., Padzys, GS., Olry, JC., Thornton, SN., Martrette, JM., Trabalon, M., 2011. Mother-Pup interactions during a short olfactory deprivation period in young rats. Develop Psychobiol. 53, 303-316.

Gelhaye, M., Trabalon, M., Martrette, JM., Legrand - Frossi, C., 2006b. Effects of early olfactory deprivation on novelty - secking behavior and primary and secondary lymphoid organs in young rats. Psychoneuroendocrinol., 31, 997 - 1008.

Graham, JM., Desjardins, C., 1980. Classical conditioning: induction of luteinizing hormone and testosterone secretion in anticipation of sexual activity. Science $210-4473$, 10391041.

Hennessy, MB., Levine, S., 1978. Sensitive pituitary-adrenal responsiveness to varying intensities of psychological stimulation. Physiol Behav. 21, 295-297.

Hongo, T., Hakuba, A., Shiota, K., Naruse, I., 2000. Suckling dysfunction caused by defects in the olfactory system in genetic arhinencephaly mice. Biol. Neonate 78, 293-299.

Hudson, R., 1993. Olfactory imprinting. Curr. Opin. Neurobiol. 3, 548-552.

Jacob, S., Hayreh, DJ., McClintock, MK., 2001. Contex-dependent effects of steroid chemosignals on human physiology and mood. Physiol. Behav. 74, 15-27.

Leon, M., 1992. Neuroethology of olfactory preference development. J. Neurobiol. 23-10, 1557-1573.

Macrides, F., Bartke, A., Fernandez, F., D’Angelo, W., 1974. Effects of exposure to vaginal odor and receptive females on plasma testosterone in the male hamster. Neuroendocrinology 15-6, 355-364.

Matochik, JA., Barfield, RJ., 1991. Hormonal control of precopulatory sebaceous scent marking and ultrasonic mating vocalizations in male rats. Horm. Behav. 25, 445-460.

Meek, LR., Romeo, RD., Novak, CM., Sisk, CL., 1997. Actions of testosterone in prepubertal and postpubertal male hamsters: dissociation of effects on reproductive behaviour and brain androgen receptor immunoreactivity. Horm. Behav. 31-1, 75-88.

Meredith, M., 1986. Vomeronasal organ removal before sexual experience impairs male hamster mating behaviour. Physiol Behav. 36, 737-743.

Meredith, M., 1998. Vomeronasal, olfactory, hormonal convergence in the brain. Cooperation or coincidence? Ann. N.Y. Acad. Sci. 855, 349-361. 
Meredith, M., Fernandez-Fewell, G., 1994. Vomeronasal system, LHRH, and sex behaviour. Psychoneuroendocrinology 19, 657-672.

Meredith, M., Howard, G., 1992. Intracerebroventricular LHRH relieves behavioural deficits due to vomeronasal organ removal. Brain Res. Bull. 29, 75-79.

Moore, CL., 1992. The role of maternal stimulation in the development of sexual behavior and its neural masis. Ann N Y Acad Sci. 662, 160-177.

Müller-Schwarze, D., Müller-Schwarze, C., 1971. Olfactory imprinting in a precocial mammal. Nature 229, 55-56.

O’Connell, RJ., Singer, AG., Macrides, F., Pfaffmann, C., Agosta, WC., 1978. Responses of the male golden hamster to mixtures of odorants identified from vaginal discharge. Behav. Biol. 24, 244-255.

Padzys, GS., Martrette, JM., Tankosic, C., Thornton, SN., Trabalon, M., 2011a. Effects of short term forced oral breathing: physiological changes and structural adaptation of diaphragm and orofacial muscles in rats. Arch Oral Biol., 56, 1646-1654.

Padzys, GS., Tankosic, C., Martrette, JM., Trabalon, M., 2012. Craniofacial development and physiological state after early oral breathing in rats. Eur. J. Oral Sci. 120, 21-28.

Padzys, GS., Thornton, SN., Martrette, JM., Trabalon, M., 2011b. Effects of short term forced oral breathing in rat pups on weight gain, hydration and stress. Physiol Behav., 102, 175180.

Pfeiffer, CA., Johnston, RE., 1992. Socially stimulated androgen surgesin male hamsters: the roles of vaginal secretions, behavioural interactions, and housing conditions. Horm. Behav. 26-2, 283-293.

Pfister, HP., 1979. The glucocorticosterone response to novelty as a psychological stressor. Physiol Behav 23, 649-652.

Pfister, HP., King, MG., 1976. Adaptation of the glucocorticosterone response to novelty. Physiol Behav. 17, 43-46.

Retana-Márquez, S., Bonilla, JH., Vázquez-Palacios, G., Martinez-Garcia, R., VelázquezMoctezuma, J., 2003. Changes in masculine sexual behavior, corticosterone and testosterone in response to acute and chronic stress in male rats. Horm. Behav. 44, 327 337.

Richardson, HN., Nelson, ALA., Ahmed, EI., Parfitt, DB., Romeo, RD., Sisk, CL. 2004. Female pheromones stimulate release of luteinizing hormone and testosterone without altering GnRH mRNA in adult male Syrian hamsters (Mesocricetus auratus). Gen Comp Endocrinol. 138, 211-217. 
Risser, JM., Slotnick, BM., 1987. Suckling behaviour in rat pups with lesions which destroy the modified glomerular complex. Brain Research Bull 19, 275-281.

Romeo, RD., Wade, J., Venier, JE., Sisk, CL., 1999. Androgenic regulation of hypothalamic aromatase activity in prepubertal and postpubertal male golden hamsters. Endocrinology $140-1,112-117$.

Rossier, J., Schenk, F., 2003. Olfactory and/or visual cues for spatial navigation through ontogeny: olfactory cues enable the use of visual cues. Behav. NEurosci. 117-34, 12-25.

Seiden, AM., Duncan, HJ., 2001. The diagnosis of a conductive olfactory loss. Laryngoscope $111,9-14$.

Stern, JJ., 1970. Responses of male rats to sex odors'. Physiol Behav. 5, 519-524.

Wirsig-Wiechmann, CR., 2001. Function of gonadotropin-releasing hormone in olfaction. Keio J. Med. 50, 81-85.

Wood, RI., Johnson, LR., Chu, L., Schad, C., Self, DW., 2004. Testosterone reinforcement: intravenous and intracerebroventricular self-administration in male rats and hamsters. Psychopharmacol. 171-3, 298-305. 
Table 1: Effects in male rats with and without neonatal nasal obstruction on body weight, nasal open, plasma glucose, proteins and lipid levels at 110 days of age.

Values are means \pm SE. $N=15$ rats per group. Analysis of ANOVA: triglycerides: $F=3.26$ at two degrees of freedom $=p<0.05$; cholesterol: $F=4.51$ at two degrees of freedom $=p<0.05$; Analysis of Tukey test: ${ }^{*} \mathrm{p}<0.05$ versus untreated and sham. NS $=$ not significant.

Table 2: Effects in male rats with and without neonatal nasal obstruction on plasma $17 \beta$ estradiol and progesterone levels at 110 days of age.

Values are means \pm SE. $\mathrm{N}=15$ rats per group. Analysis by ANOVA: NS = not significant 
Figure 1: Time line of experimental protocol.

Figure 2: Latency of the first choice of male rats at 110 days of age in a two-choice situation: (A) "fresh bedding vs nest bedding of male" and (B) «nest bedding estrus untreated female $v s$ nest bedding anestrus untreated female » with untreated group (UT), sham group (SH), and animals with nasal obstruction at 8 days $(\mathrm{RbNO})$. Values are means $\pm \mathrm{SE}(\mathrm{n}=15$ rats $/$ group).

Analysis of Tukey test: NS = not significantly different; * significantly different from "fresh bedding of male" at $p=0.03, *$ significantly different from "anestrus bedding" and from UT and $\mathrm{SH}$ groups at $p=0.05$.

Figure 3: Impact of early nasal obstruction on male rats' behavior in a two-choice situation: (A) "fresh bedding vs nest bedding of male" and (B) «nest bedding estrus untreated female $v s$ nest bedding anestrus untreated female ». Distribution of the total time spent in each arm of the T-maze with untreated group (UT), sham group (SH), and animals with nasal obstruction at 8 days $(\mathrm{RbNO})$. Values are means $\pm \mathrm{SE}$ ( $\mathrm{n}=15$ rats $/$ group).

3A: Analysis of Tukey test: NS not significantly different; $* * *$ significantly different from fresh and nest for all 3 groups of rat at $p<0.005$.

3B: Analysis of Tukey test: NS not significantly different; ** significantly different from UT and SH groups at $p=0.01 ; * * *$ significantly different from UT and SH groups at $p<0.005$.

Figure 4: Distribution of the time spent in each arm of the radial arm maze with untreated group (UT), sham group ( $\mathrm{SH})$, and animals with nasal obstruction at 8 days (RbNO) in a three-choice situation: «nest bedding untreated female (UT) versus nest bedding sham female (SH) versus nest bedding RbNO female $\gg(\mathrm{n}=15$ rats / group).

Analysis of Tukey test: NS not significantly different; * significantly different between different arms at $p=0.05 ; * *$ significantly different from UT and SH males at $p=0.01$.

Figure 5: Impact of early nasal obstruction on plasma corticosterone level before and after behavior tests in untreated (UT) group, sham group (SH) and animals with nasal obstruction at 8 days $(\mathrm{RbNO})$. Values are means $\pm \mathrm{SE}(\mathrm{n}=15$ rats per group). 
Analysis of Tukey test: NS not significantly different; * significantly different from UT and SH before behavioral tests at $p<0.05$; ** significantly different from other groups after behavioral tests and different from other groups before behavioral tests at $p<0.01$.

Figure 6: Plasma sexual testosterone levels in untreated (UT) group, sham group (SH) and animals with nasal obstruction at 8 days (RbNO) before and after behavioral tests. Values are means $\pm S E(n=15$ rats per group).

Analysis of Tukey test: NS not significantly different; * significantly different from UT and SH before behavioral tests at $p<0.05$; **** significantly different from UT and SH groups after behavioral tests at $p<0.0001$. 


\section{Table 1}

Body weight, nasal open, plasma glucose, proteins, and lipid levels at 110 days of age in male rats with and without neonatal nasal obstruction.

Values are means \pm SE. $n=15$ rats per group. Analysis by ANOVA: * nasal open: $\mathrm{F}=7.22$ at two degrees of freedom, $\mathrm{P}=0.004 ;$ *triglycerides: $\mathrm{F}=3.26$ at two degrees of freedom, $\mathrm{P}<$ 0.05; * cholesterol: $\mathrm{F}=4.51$ at two degrees of freedom, $\mathrm{P}<0.05 ;{ }^{\mathrm{a}} \mathrm{p}<0.05$ versus untreated and sham. $\mathrm{NS}=$ not significant.

\begin{tabular}{lcccccc}
\hline Groups & $\begin{array}{c}\text { Body } \\
\text { weight } \\
(\mathrm{g})\end{array}$ & $\begin{array}{c}\text { Nasal } \\
\text { diameter } \\
(\mu \mathrm{m})\end{array}$ & $\begin{array}{c}\text { Glucose } \\
(\mathrm{mg} / \mathrm{dL})\end{array}$ & $\begin{array}{c}\text { Proteins } \\
(\mathrm{mg} / \mathrm{mL})\end{array}$ & $\begin{array}{c}\text { Triglycerides } \\
(\mathrm{mg} / \mathrm{dL})\end{array}$ & $\begin{array}{c}\text { Cholesterol } \\
(\mathrm{mg} / \mathrm{dL})\end{array}$ \\
\hline Untreated & $401 \pm 11$ & $239 \pm 1$ & $235 \pm 7$ & $151 \pm 6$ & $93 \pm 3$ & $115 \pm 10$ \\
Sham & $421 \pm 19$ & $238 \pm 1$ & $236 \pm 12$ & $155 \pm 7$ & $99 \pm 5$ & $139 \pm 20$ \\
RbNO & $394 \pm 10$ & $214 \pm 1$ & $232 \pm 5$ & $132 \pm 10$ & $146 \pm 10^{\mathrm{a}}$ & $195 \pm 15^{\mathrm{a}}$ \\
\hline \multirow{2}{*}{ ANOVA } & $\mathrm{NS}$ & $*$ & $\mathrm{NS}$ & $\mathrm{NS}$ & $*$ & $*$ \\
\hline
\end{tabular}




\section{Table 2}

Plasma $17 \beta$-oestradiol, and progesterone levels at 110 days of age in male rats with and without neonatal nasal obstruction.

Values are means \pm SE. $\mathrm{N}=15$ rats per group. Analysis by ANOVA: NS = not significant.

\begin{tabular}{lcc}
\hline Groups & $\begin{array}{c}\mathbf{1 7} \boldsymbol{\beta} \text { - estradiol } \\
(\mathrm{ng} / \mathrm{mL})\end{array}$ & $\begin{array}{c}\text { Progesterone } \\
(\mathrm{ng} / \mathrm{mL})\end{array}$ \\
\hline Untreated & $1.3 \pm 0.1$ & $2.1 \pm 0.3$ \\
Sham & $1.7 \pm 0.2$ & $1.9 \pm 0.3$ \\
Nasal obstruction & $1.9 \pm 0.2$ & $2.3 \pm 0.2$ \\
\hline & $\mathrm{NS}$ & $\mathrm{NS}$ \\
ANOVA & &
\end{tabular}


Figure 1 :

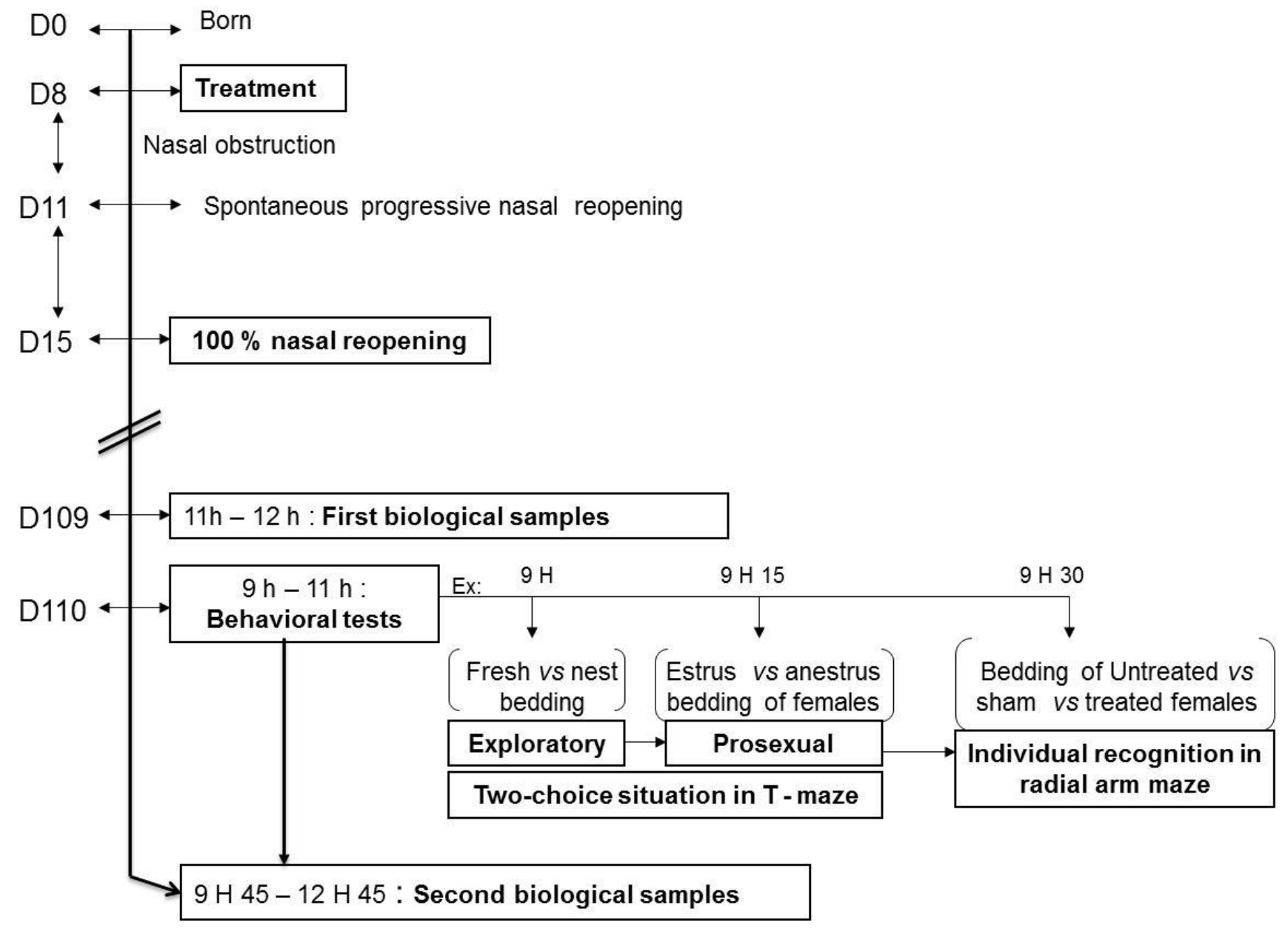


Figure 2 :

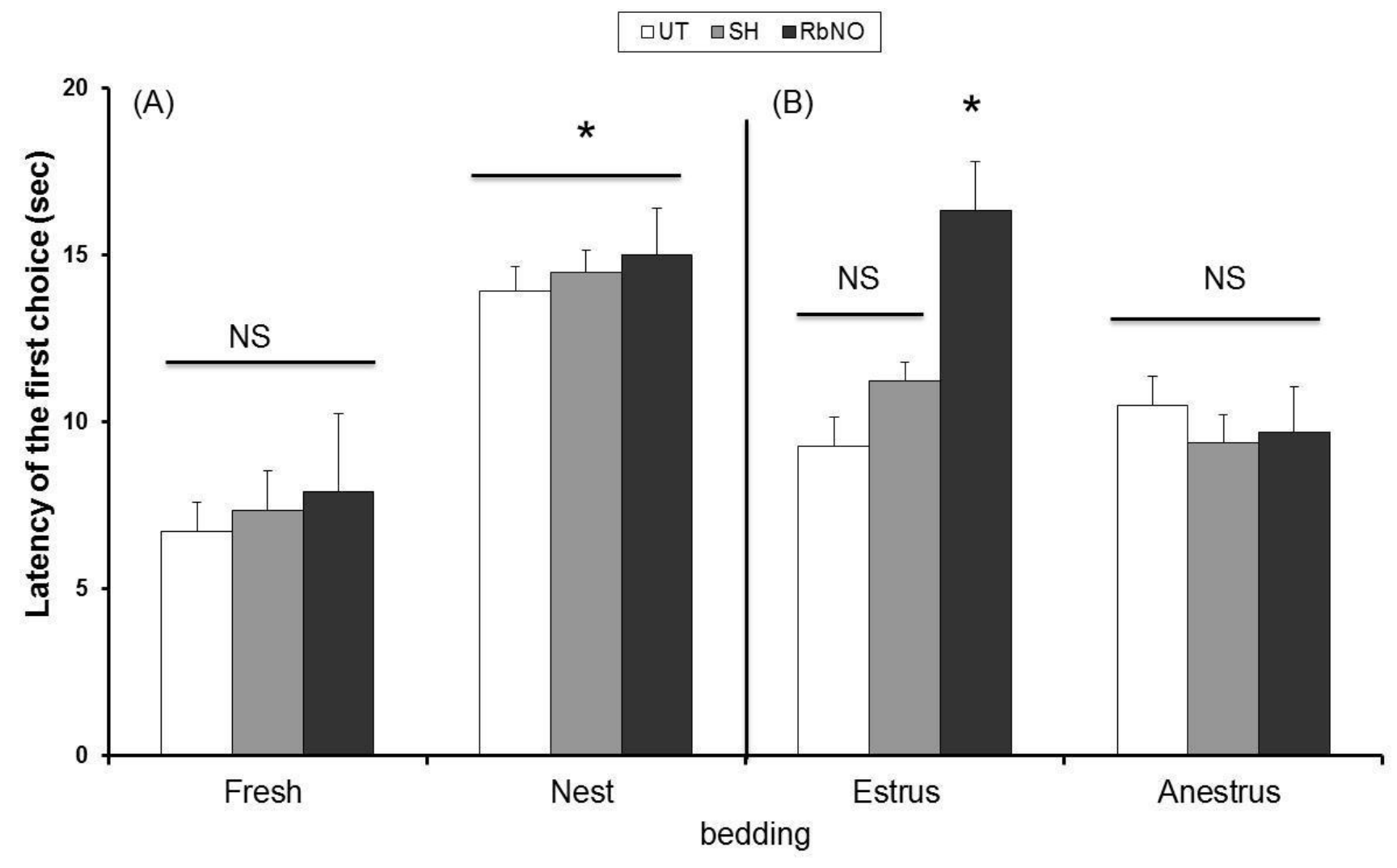


Figure 3 :

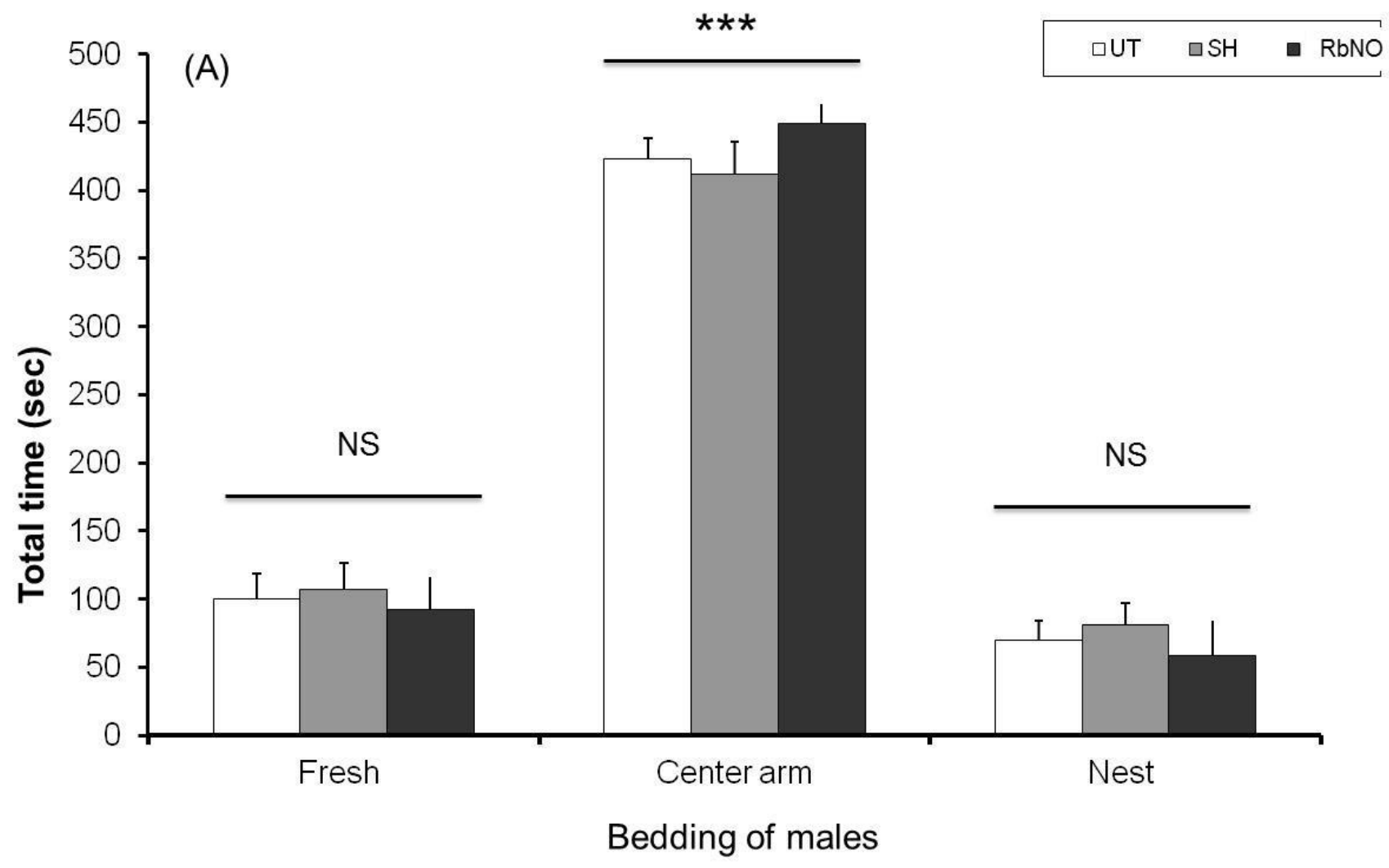

(B)

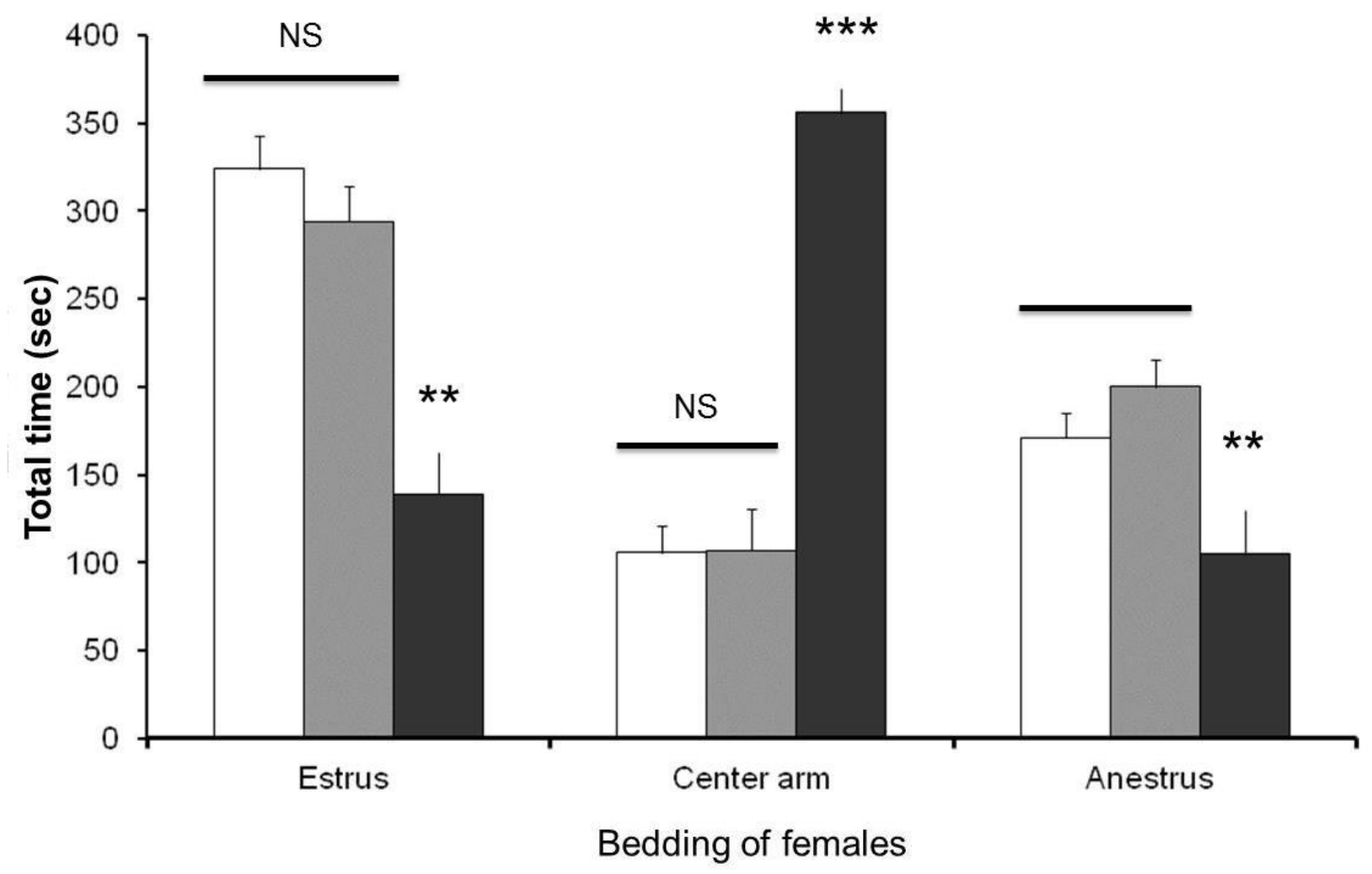


Figure 4 :

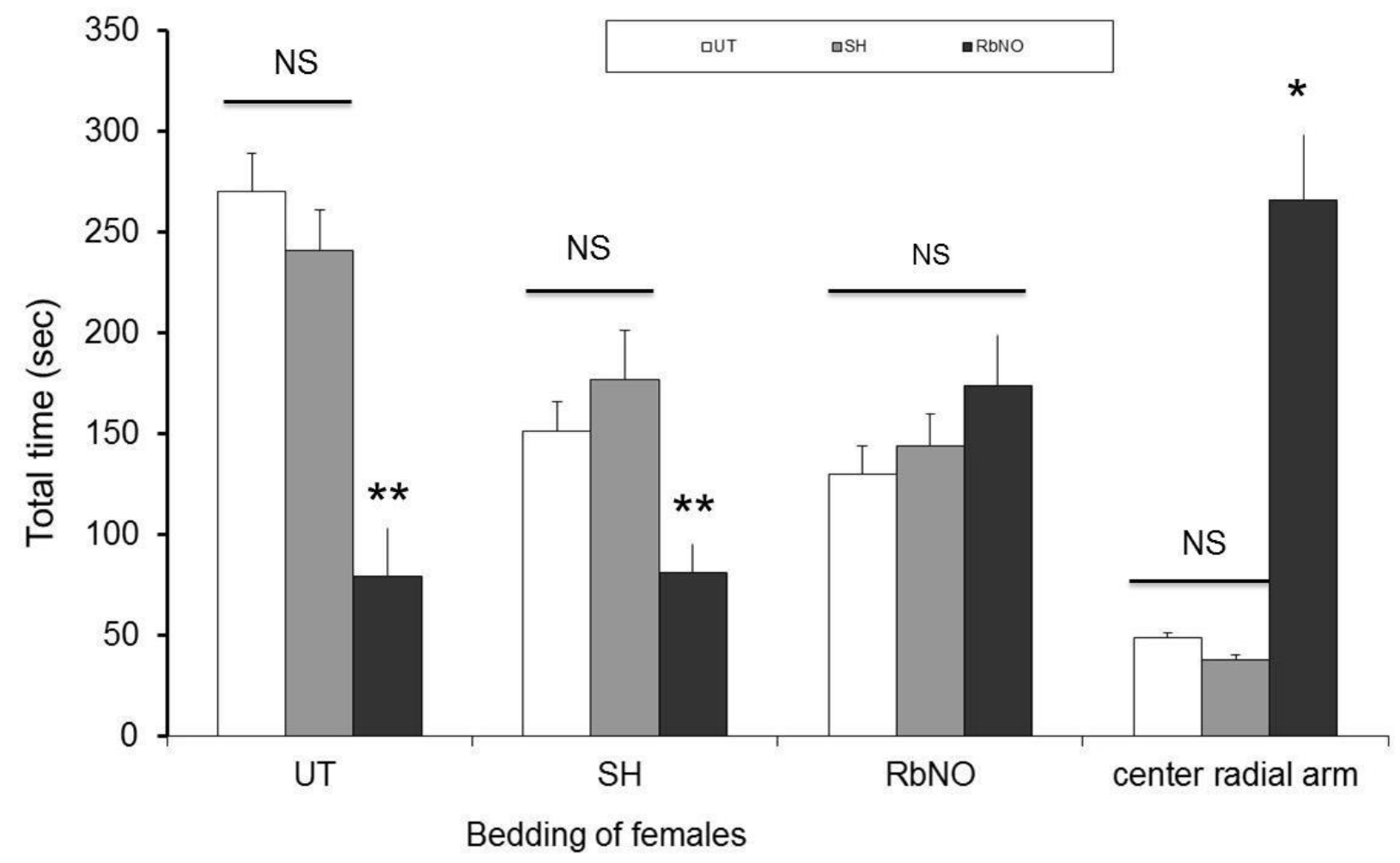


Figure 5 :

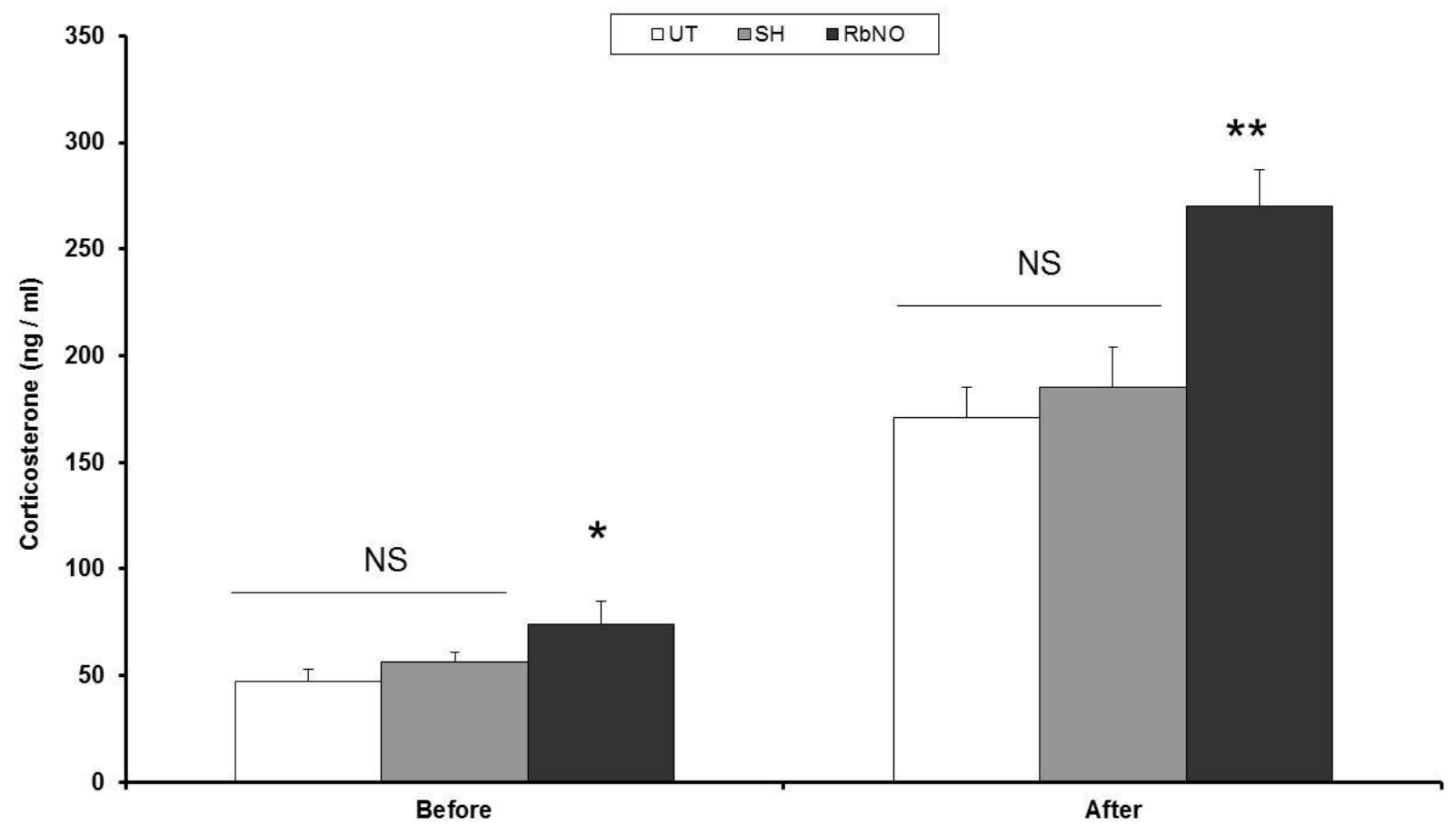

Behavioural tests 
Figure 6 :

$$
\text { 口UT } \square \mathrm{SH} \quad \square \mathrm{RbNO}
$$

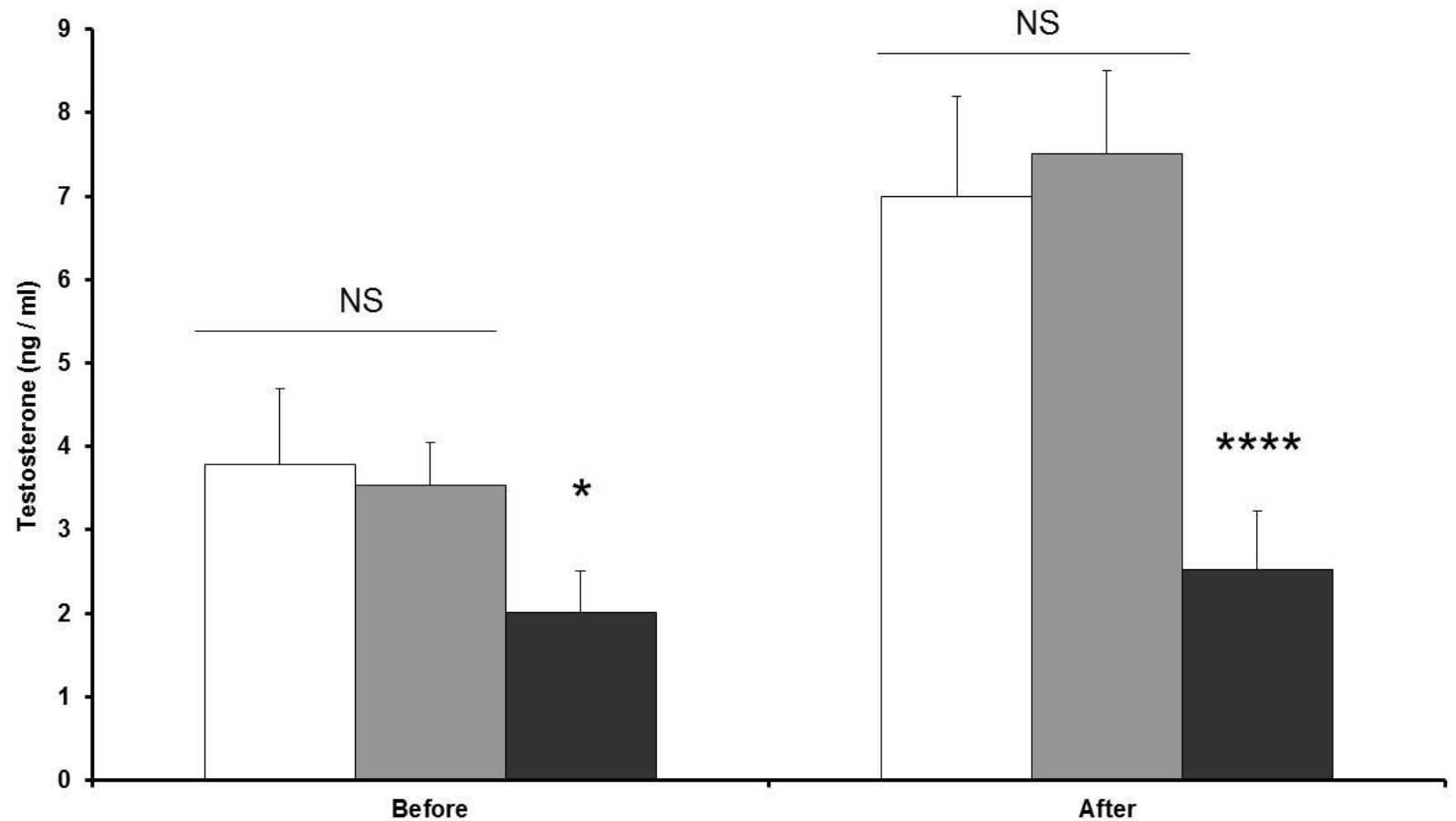

Behavioural tests 